\title{
Interactive comment on "Brief Communication: Outburst floods triggered by periodic drainage of subglacial lakes, Isunguata Sermia, West Greenland” by Stephen J. Livingstone et al.
}

Stephen J. Livingstone et al.

s.j.livingstone@sheffield.ac.uk

Received and published: 19 September 2019

Please see attached pdf.

Please also note the supplement to this comment:

https://www.the-cryosphere-discuss.net/tc-2019-137/tc-2019-137-AC1-

supplement.pdf 